\title{
Complex Variable Solutions for Forces and Displacements of Circular Lined Tunnels
}

\author{
Xingbo Han $\left(\mathbb{D},{ }^{1,2}\right.$ Yongxu Xia, ${ }^{1}$ Xing Wang $\mathbb{D}^{1},{ }^{1}$ and Lunlei Chai $\mathbb{D}^{1}$ \\ ${ }^{1}$ School of Highway, Chang'an University, Xi'an 710064, Shaanxi, China \\ ${ }^{2}$ School of Civil and Environmental Engineering, The University of New South Wales, NSW 2552, Sydney, Australia \\ Correspondence should be addressed to Xingbo Han; xingbo.han@chd.edu.cn
}

Received 2 June 2018; Revised 18 July 2018; Accepted 1 September 2018; Published 16 September 2018

Academic Editor: Francesco Pellicano

Copyright (C) 2018 Xingbo Han et al. This is an open access article distributed under the Creative Commons Attribution License, which permits unrestricted use, distribution, and reproduction in any medium, provided the original work is properly cited.

A complex variable method for solving the forces and displacements of circular lined tunnels is presented. Complex potentials for the stresses and displacements are expressed in the term of series expression. The undetermined coefficients of the complex potentials are obtained according to the stress boundary conditions along the lining inner surface and the displacement and surface traction boundary condition along the lining and rock-mass interface. Solutions for the stresses and displacements of the tunnel lining and rock-mass are then established by applying Muskhekishvili's complex variable method. In addition, forces solutions for linings are presented based on the tangential stress at the two boundaries. Examples are finally established to reveal the applicability and accuracy of the proposed method. The effects of the degrees from the tunnel crown to the invert, coefficient of the lateral earth pressure, and distance from the rock-mass to the interface on the regulations of the lining forces and rock-mass stresses are also thoroughly investigated.

\section{Introduction}

Tunnels are essential infrastructures that play a pivotal role in water conveyance, transportation, and mining, as well as military engineering. Linings are the most important structures to ensure the safety of the tunnel system. It has been of high interest to determine the stress and displacement distribution of the surrounding rock-mass and the force and deformation response of the lining with high level of accuracy [1-9].

Numerical simulation and analytic method, as well as in situ or indoors experiment, are the three main approaches used in practice to predict the stresses and deformations of the tunnel lining and surrounding rock-mass. Extensive numerical simulations have been performed in recent years. Möller and Vermeer (2008) applied finite element method and researched the lining forces and soil displacements of two under construction tunnels [10]. Liu et al. (2017) preformed a simulation of the Gongti North Road tunnel of Beijing Metro Line 10 built by the PBA method to determine the stress state of the structure under construction [11]. Also, a series of 3D FEM analysis were performed by Avgerinos et al. (2017) to discuss the lining forces and deformation of the future Crossrail tunnel [12]. Numerical method can be used to solve problems with nonlinear soil property (elastoplastic or elastoviscoplastic) and complex boundary conditions. However, most of the numerical simulations are applied to certain engineering cases and are difficult to give an understanding of how final solutions are influenced by different parameters $[3,13-15]$. The solution obtained by analytical method is still in great significance for in-depth analysis of tunnel engineering.

To derive the analytic solutions for the structure forces and displacements, many researchers treated the tunnel lining as shallow arches. Pi et al. (2002) investigated the stress and buckling behaviour of the shallow arch under the radial uniformly distributed load by using the energy method [16]. Gao et al. (2014) combined the structural analysis and material uncertainties of arches and presented the results of the axial compressive force, bending moment, and axial displacement [17]. These methods presented an access to the assessment of the circular structures but are still difficult to solve the lining and rock-mass problems due to the difference between boundary conditions of the models and field. 


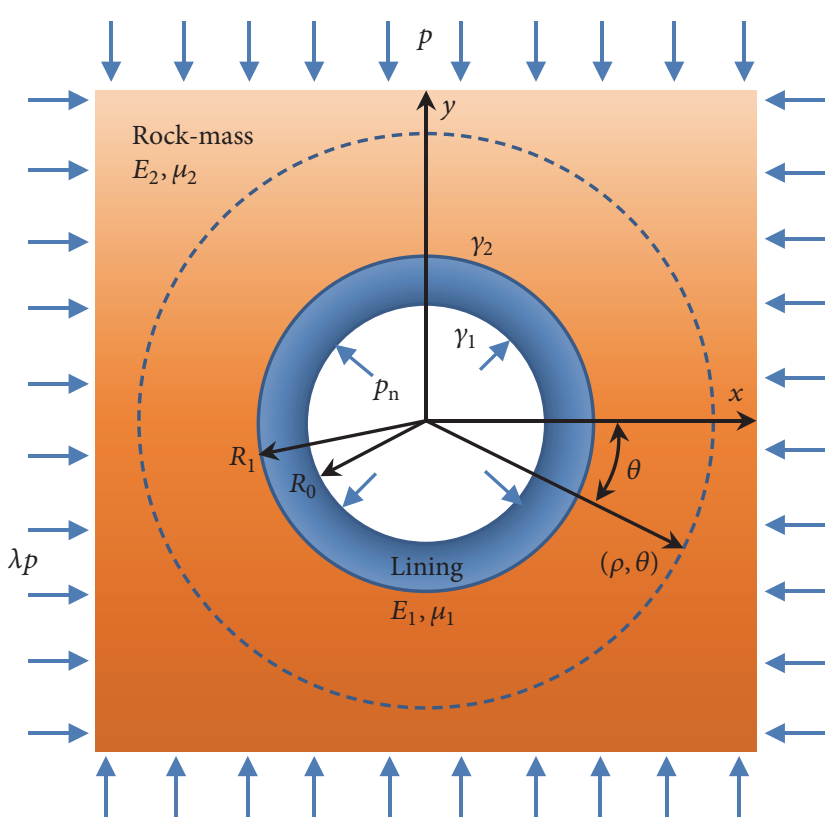

FIGURE 1: Lined tunnel under an initial stress field.

The theoretical methods for circular tunnels are also fully developed. Based on the complex potential functions and conformal mapping, Muskhekishvili and Radok (1953) proposed a complex variable method to investigate the stress components and deformation within the material [18]. This method was also used by Lekhnitskii (1968) to determine the closed-form solutions for the stresses around a circular hole [19]. Then Verruijt (1997) applied the complex variable method on the circular tunnel in an elastic half-plane [20]. Similar method was used by Manh et al. (2013) to develop a semianalytical solution for an unlined circular tunnel excavated in a transversely isotropic formation with nonlinear behaviour [21]. However, the interaction between the tunnel lining and geomaterial was ignored in these methods. Two different regions should be assumed when the lining is considered and thus increased the complexity of the problem.

This study aims to establish solutions for forces and displacements of lined tunnels by using Muskhekishvili's complex variable method. Some instantaneous elastic deformation occurs in the surrounding rock-mass before the lining is installed [13]. Thus, it is reasonable to consider the support delay of the lining after the tunnel is excavated. A release coefficient $\eta$ is assumed herein to consider the support delay and the interaction between the lining and surrounding rock-mass. The inner surface of the transportation (highway, railway, metro, etc.) tunnel lining is a free boundary condition where the load action is zero. Nevertheless, the situation is different for pressured water-conveyance tunnels. Hence, a radial pressure $p_{\mathrm{n}}$ is considered to cover both situations ( $p_{\mathrm{n}}$ equals zero for transportation tunnels). Stresses and displacements are firstly derived by expressing the complex potentials in terms of series expression. Then, three governing equations to determine the unknown coefficients of the potentials are obtained based on the stress boundary conditions at the lining inner surface and the displacement and surface force boundary conditions at the lining and rock-mass interface. In addition, according to the knowledge of the mechanics of materials, forces solutions for linings are also presented by using the tangential stress result at two boundaries. Finally, parameter analysis through examples is established to acquire regulations for the forces and displacements of the lining and rock-mass, respectively. Guidance for the design and construction of the circular tunnel is also presented based on the result of parameter analysis.

\section{Complex Variable Method for Lined Circular Tunnels}

The problem can be considered as a reinforced hole in an infinite plane subjected to a uniform stress state at infinity while the tunnel is located at a great depth compared with the tunnel dimension. The infinite plane on the complex plane is divided into two isotropic homogenous regions considering both the lining and surrounding rock-mass. As shown in Figure 1, the two regions are bounded by contours $\gamma_{1}$ and $\gamma_{2}$, which represent the inner and outer boundaries of the lining, respectively. The conformal mapping function of the circle can be expressed as follows [13]:

$$
z=\omega(\zeta)=R \zeta=R \mathrm{e}^{\mathrm{i} \theta}
$$

where $\mathrm{i}=\sqrt{-1}$ and $R$ is the radius of the circle.

The stress components provided by Muskhelishvli and Radok (1953) [18] based on the complex variable method are as follows:

$$
\begin{aligned}
\sigma_{x}+\sigma_{y} & =4 \operatorname{Re}\left[\varphi^{\prime}(z)\right] \\
\sigma_{y}-\sigma_{x}+2 \mathrm{i} \tau_{x y} & =2\left[\bar{z} \varphi^{\prime \prime}(z)+\psi^{\prime}(z)\right]
\end{aligned}
$$

where $\sigma_{x}$ and $\sigma_{y}$ are the horizontal and vertical stress components, respectively, and $\tau_{x y}$ is the shear stress. $\varphi(z)$ and $\psi(z)$ 


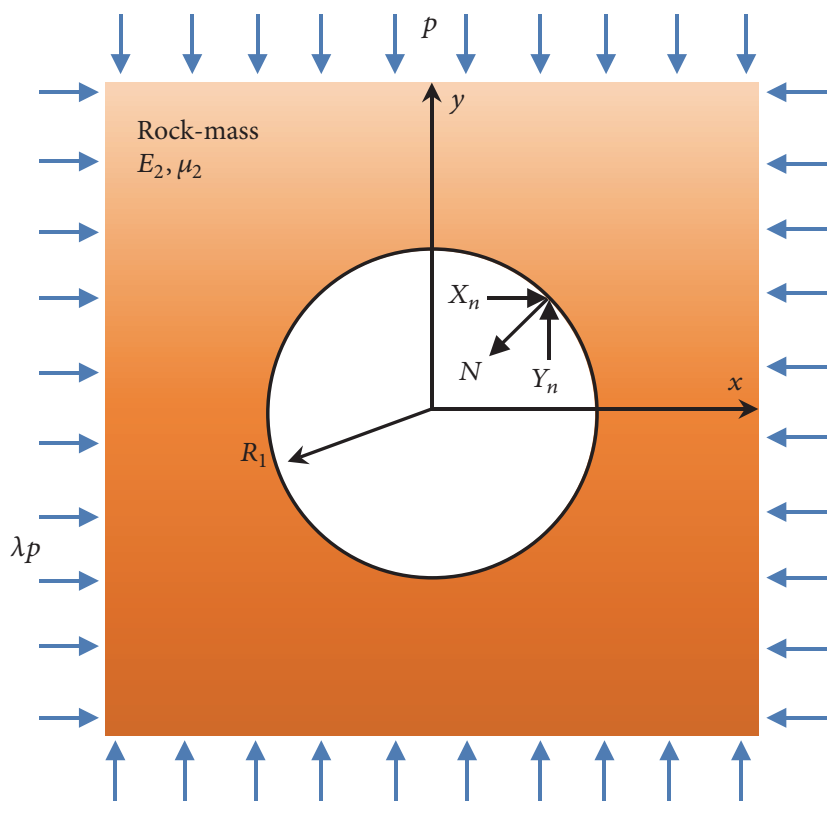

FIGURE 2: Surface force components on the boundary of an unlined tunnel.

are two complex potentials, and $\operatorname{Re}\{\}$ denotes the real part of \{\} . lows:

The displacement components can be described as fol-

$$
2 G\left(u_{x}+\mathrm{i} u_{y}\right)=\kappa \varphi(z)-z \overline{\varphi^{\prime}(z)}-\overline{\psi(z)}
$$

where $u_{x}$ and $u_{y}$ are the horizontal and vertical displacement components, respectively, $G$ is the shear modulus, and $\kappa$ is a parameter related to Poisson's ratio $v$ and is as follows:

$$
\kappa= \begin{cases}3-4 \mu & \text { planestrian } \\ \frac{3-4 \mu}{1+\mu} & \text { planestress }\end{cases}
$$

Denote the total displacement of the rock-mass induced by the excavation without support on the orthogonal curvilinear coordinate system as $u_{\rho 1}{ }^{\mathrm{R}}+\mathrm{i} u_{\theta 1}{ }^{\mathrm{R}}$; from (3), it can be expressed as follows $[22,23]$ :

$$
\begin{aligned}
u_{\rho 1}^{\mathrm{R}}+\mathrm{i} u_{\theta 1}^{\mathrm{R}} & =e^{-i \theta}\left(u_{x 1}{ }^{\mathrm{R}}+\mathrm{i} u_{y 1}{ }^{\mathrm{R}}\right) \\
& =\frac{1}{2 G_{1}} e^{-i \theta}\left[\kappa_{1} \varphi_{1}(z)-z \overline{\varphi_{1}^{\prime}(z)}-\overline{\psi_{1}(z)}\right]
\end{aligned}
$$

where $u_{\rho 1}{ }^{\mathrm{R}}$ and $u_{\theta 1}{ }^{\mathrm{R}}$ are the radial and tangential displacement components, respectively, $G_{1}$ and $\kappa_{1}$ refer to the parameters of the surrounding rock-mass, and, in order to show discrimination, the complex potentials for the situation without lining are denoted as $\varphi_{1}(z)$ and $\psi_{1}(z)$.

The surface tractions along the boundaries satisfy the following equation:

$$
\mathrm{i} \int_{A}^{B}\left(X_{n}+\mathrm{i} Y_{n}\right) \mathrm{d} s=\varphi_{1}(z)+z \overline{\varphi_{1}{ }^{\prime}(z)}+\overline{\psi_{1}(z)}
$$

where $X_{n}$ and $Y_{n}$ are components of the surface traction vector in $x$ and $y$ directions, respectively, $A$ and $B$ are points at the boundary, and $\mathrm{d} s$ is the arc length.

As shown in Figure 2, $p$ is the vertical component of in situ stress, and $\lambda$ is the lateral pressure coefficient. The rockmass is in initial stress state where $\sigma_{x}{ }^{0}=-\lambda p, \sigma_{y}{ }^{0}=-p$, and $\sigma_{x y}{ }^{0}=0$ before the excavation of the tunnel. The surface tractions can be determined by the initial stress field as follows [13]:

$$
X_{n}+\mathrm{i} Y_{n}=-\lambda p \frac{\mathrm{d} y}{\mathrm{~d} s}+\mathrm{i} p \frac{\mathrm{d} y}{\mathrm{~d} s}
$$

The excavation of the tunnel is an application of a surface with magnitude of $-\left(X_{n}+\mathrm{i} Y_{n}\right)$ on the working face [13]. From (7), the following can be derived as

$$
\begin{aligned}
& \mathrm{i} \oint-\left(X_{n}+\mathrm{i} Y_{n}\right) \mathrm{d} s=\frac{p(1+\lambda)}{2} z+\frac{p(1-\lambda)}{2} \bar{z} \\
& z=R_{1} e^{\mathrm{i} \theta}
\end{aligned}
$$

The stress boundary condition at $\rho=R_{1}$ in the unsupported situation can be expressed as follows:

$$
\varphi_{1}(z)+z \overline{\varphi_{1}^{\prime}(z)}+\overline{\psi_{1}(z)}=\frac{p(1+\lambda)}{2} z+\frac{p(1-\lambda)}{2} \bar{z}
$$

The general solution for the complex potentials can be expressed by the following [22]:

$$
\begin{aligned}
\varphi_{1}(z)= & \frac{1}{2 \pi\left(1+\kappa_{1}\right)}(X+\mathrm{i} Y) \ln z+(B+\mathrm{i} C) z \\
& +{\varphi_{1}}^{0}(z) \\
\psi_{1}(z)= & \frac{1}{2 \pi\left(1+\kappa_{1}\right)}(X-\mathrm{i} Y) \ln z+\left(B^{\prime}+\mathrm{i} C^{\prime}\right) z \\
& +\psi_{1}{ }^{0}(z)
\end{aligned}
$$

where $X$ and $Y$ are the resultant force in $x$ and $y$ direction, respectively, $B, C, B^{\prime}, C^{\prime}$ are real constant, and functions $\varphi_{1}{ }^{0}(z)$ and $\psi_{1}{ }^{0}(z)$ can be expressed as

$$
\begin{aligned}
& \varphi_{1}^{0}(z)=a_{0}+\sum_{k=1}^{\infty} a_{k} z^{-k} \\
& \psi_{1}^{0}(z)=b_{0}+\sum_{k=1}^{\infty} b_{k} z^{-k}
\end{aligned}
$$

According to [20], in this problem, $X$ and $Y$ equal zero because the surface forces on the contour are balanced force system. Since only the surface forces influence the displacement caused by the excavation, $B=C=B^{\prime}=C^{\prime}=0$. The displacement at infinity equals zero; thus $a_{0}$ and $b_{0}$ equal zero. Eq. (10) can be then expressed as

$$
\begin{aligned}
& \varphi_{1}(z)=\sum_{k=1}^{\infty} a_{k} z^{-k} \\
& \psi_{1}(z)=\sum_{k=1}^{\infty} b_{k} z^{-k}
\end{aligned}
$$


By substituting (12) into (9), the two potentials in (6) can be obtained by the following equations [13]:

$$
\begin{aligned}
& \varphi_{1}(z)=\frac{p(1+\lambda)}{2} R_{1}{ }^{2} \frac{1}{z} \\
& \psi_{1}(z)=\frac{p(1+\lambda)}{2} R_{1}{ }^{2} \frac{1}{z}+\frac{p(1+\lambda)}{2} R_{1}{ }^{4} \frac{1}{z^{3}}
\end{aligned}
$$

Substituting (13) into (5) the following equations can be obtained:

$$
\begin{gathered}
u_{\rho 1}{ }^{\mathrm{R}}+\mathrm{i}{u_{\theta 1}}^{R}=\frac{1}{2 G_{1}} e^{-i \theta}\left[\kappa_{1} \frac{p(1+\lambda)}{2} R_{1}{ }^{2} \frac{1}{z}\right. \\
+\frac{p(1+\lambda)}{2} R_{1}{ }^{2} \frac{z}{\bar{z}^{2}}-\frac{p(1+\lambda)}{2} R_{1}{ }^{2} \frac{1}{z} \\
\left.-\frac{p(1+\lambda)}{2} R_{1}{ }^{4} \frac{1}{\bar{z}^{3}}\right]
\end{gathered}
$$

Considering that the lining is installed when the displacement is $\eta$ times the total displacement of the unsupported tunnel, the displacement of the rock-mass $u_{\rho 2}{ }^{R}+i u_{\theta 2}{ }^{R}$ occurs before the support of the lining can be expressed as follows:

$$
u_{\rho 2}^{\mathrm{R}}+\mathrm{i} u_{\theta 2}{ }^{R}=\eta\left(u_{\rho 1}^{\mathrm{R}}+\mathrm{i}{u_{\theta 1}}^{R}\right)
$$

where $\eta$ is between 0 and 1 . When $\eta$ equals zero, the tunnel is supported immediately after excavation, which means no deformation occurs in the rock-mass before the tunnel is lined. This situation will not happen in the practice because no matter how fast the lining is supported, the surrounding rock will have some deformation. When $\eta$ equals 1 , the lining is applied after the total displacement has completed.

After the lining is applied, a part of the displacement of the surrounding rock-mass is restricted and can be then presented by the following equation:

$$
\begin{aligned}
& 2 G_{1}\left(u_{\rho 3}{ }^{\mathrm{R}}+\mathrm{i}{\left.u_{\theta 3}{ }^{\mathrm{R}}\right)}=e^{-\mathrm{i} \theta}\left[\kappa_{1} \varphi_{2}(z)-\overline{\varphi_{2}{ }^{\prime}(z)}-\overline{\psi_{2}(z)}\right]\right.
\end{aligned}
$$

From (15) and (16), the final displacement of the surrounding rock-mass for the lined tunnel $u_{\rho}{ }^{\mathrm{R}}+\mathrm{i} u_{\theta}{ }^{\mathrm{R}}$ can be expressed as follows:

$$
\begin{aligned}
& u_{\rho}^{\mathrm{R}}+\mathrm{i} u_{\theta}^{\mathrm{R}} \\
& =\left(u_{\rho 1}{ }^{\mathrm{R}}+\mathrm{i} u_{\theta 1}{ }^{\mathrm{R}}\right)-\left(u_{\rho 2}{ }^{\mathrm{R}}+\mathrm{i} u_{\theta 2}{ }^{\mathrm{R}}\right) \\
& +\left(u_{\rho 3}{ }^{\mathrm{R}}+\mathrm{i} u_{\theta 3}{ }^{\mathrm{R}}\right) \\
& =\frac{1-\eta}{2 G_{1}} e^{-\mathrm{i} \theta}\left[\kappa_{1} \varphi_{1}(z)-z \overline{\varphi_{1}^{\prime}(z)}-\overline{\psi_{1}(z)}\right] \\
& +\frac{1}{2 G_{1}} e^{-\mathrm{i} \theta}\left[\kappa_{1} \varphi_{2}(z)-z \overline{\varphi_{2}^{\prime}(z)}-\overline{\psi_{2}(z)}\right]
\end{aligned}
$$

The displacement of the lining can be derived by the following equation:

$$
2 G_{2}\left(u_{\rho}{ }^{\mathrm{L}}+\mathrm{i} u_{\theta}{ }^{\mathrm{L}}\right)=\kappa_{2} \varphi_{3}(z)-z \overline{\varphi_{3}{ }^{\prime}(z)}-\overline{\psi_{3}(z)}
$$

where $u_{\rho}{ }^{\mathrm{L}}$ and $u_{\theta}{ }^{\mathrm{L}}$ are the displacement components of any point of the lining in the radial and tangential directions and $G_{2}$ and $\kappa_{2}$ refer to the parameters of the lining concrete.

Functions in (16) - (18) can be expressed using the Taylor and Laurent series as

$$
\begin{aligned}
& \varphi_{2}(z)=\sum_{k=1}^{\infty} c_{k} z^{-k} \\
& \psi_{2}(z)=\sum_{k=1}^{\infty} d_{k} z^{-k} \\
& \varphi_{3}(z)=\sum_{k=1}^{\infty} e_{k} z^{-k}+\sum_{k=1}^{\infty} f_{k} z^{k} \\
& \psi_{3}(z)=\sum_{k=1}^{\infty} g_{k} z^{-k}+\sum_{k=1}^{\infty} h_{k} z^{k}
\end{aligned}
$$

Three boundary conditions used to solve the undetermined coefficients $\left(c_{k}, d_{k}, e_{k}, f_{k}, g_{k}, h_{k}\right)$ of the potentials $\left(\varphi_{2}(\zeta), \psi_{2}(\zeta), \varphi_{3}(\zeta), \psi_{3}(\zeta)\right)$ are as follows:

(i) the normal stress at the inner boundary of lining at $\gamma_{1}$ equals $-p_{n}$;

(ii) the surface tractions are continuous at the interface $\gamma_{2}$ from both surrounding rock-mass side and lining side;

(iii) the displacement is continuous at the interface $\gamma_{2}$ from both surrounding rock-mass side and lining side. In the engineering practice, rock bolts which restrict the tangential displacement of the lining will be applied. Thus, displacement in both radial and tangential directions are considered continuous.

Using (2), the stress components in the orthogonal curvilinear coordinate system can be rewritten as follows:

$$
\begin{aligned}
\sigma_{\rho}+\sigma_{\theta} & =\sigma_{x}+\sigma_{y}=4 \operatorname{Re}\left[\varphi^{\prime}(z)\right] \\
\sigma_{\theta}-\sigma_{\rho}+2 \mathrm{i} \tau_{\rho \theta} & =2\left[\bar{z} \varphi^{\prime \prime}(z)+\psi^{\prime}(z)\right] e^{2 \mathrm{i} \theta}
\end{aligned}
$$

where $\sigma_{\rho}$ is the normal stress and $\sigma_{\theta}$ is the tangential stress.

From (14), the normal stress condition of the lining at inner boundary $\gamma_{1}\left(z=R_{0} e^{i \theta}\right)$ can be expressed as follows:

$$
2 \operatorname{Re}\left[\varphi_{3}^{\prime}(z)\right]-\left[\bar{z} \varphi_{3}^{\prime \prime}(z)+\psi_{3}^{\prime}(z)\right] e^{2^{\mathrm{i} \theta}}=-p_{\mathrm{n}}
$$

Substituting (19) into (21), the following equations can be obtained:

$$
\begin{aligned}
& 2 f_{1}+g_{1} R_{0}^{-2}+2\left(f_{2} R_{0}+g_{2} R_{0}^{-3}\right) \cos \theta+2 i\left(-f_{2} R_{0}\right. \\
& \left.\quad+g_{2} R_{0}^{-3}\right) \sin \theta+\sum_{k=1}^{\infty}\left[-2 k e_{k} R_{0}{ }^{-k-1}\right. \\
& \left.\quad+2(k+2) f_{k+2} R_{0}^{k+1}+(k+2) g_{k+2} R_{0}{ }^{-k-3}\right] \cos (k \\
& \quad+1) \theta+\sum_{k=1}^{\infty}\left[-k(k+1) e_{k}{R_{0}}^{-k-1}\right.
\end{aligned}
$$




$$
\begin{aligned}
& \left.-(k+2)(k+1) f_{k+2} R_{0}{ }^{k+1}-k h_{k} R_{0}{ }^{k-1}\right] \cos (k+1) \\
& \cdot \theta \\
& +i \sum_{k=1}^{\infty}\left[\begin{array}{c}
-(k+2) g_{k+2} R_{0}{ }^{-k-3}+k(k+1) e_{k} R_{0}{ }^{-k-1} \\
-(k+2)(k+1) f_{k+2} R_{0}^{k+1}-k h_{k} R_{0}^{k-1}
\end{array}\right] \\
& \cdot \sin (k+1) \theta=p_{\mathrm{n}}
\end{aligned}
$$

Eq. (22) should be applicable to any $\theta$ around the lining. Hence the following equations can be obtained:

$$
\begin{aligned}
& 2 f_{1}+g_{1} R_{0}^{-2}=-p_{\mathrm{n}} \\
& g_{2}=f_{2}=0 \\
& e_{k} R_{0}^{-k-1}+(k+2) f_{k+2} R_{0}^{k+1}+h_{k} R_{0}^{k-1}=0 \text {, } \\
& (k \geq 1) \\
& -k e_{k} R_{0}^{-k-1}+f_{k+2} R_{0}^{k+1}+g_{k+2} R_{0}^{-k-3}=0, \\
& (k \geq 1)
\end{aligned}
$$

The surface tractions condition at the interface $\gamma_{2}$ $\left(z=R_{1} e^{\mathrm{i} \theta}\right)$ can be presented as follows:

$$
\varphi_{2}(z)+z \overline{\varphi_{2}^{\prime}(z)}+\overline{\psi_{2}(z)}=\varphi_{3}(z)+z \overline{\varphi_{3}^{\prime}(z)}+\overline{\psi_{3}(z)}
$$

Substituting (19) into (24), the following equations can be derived:

$$
\begin{aligned}
& \sum_{i=1}^{n} \mathrm{c}_{k} R_{1}^{-k} e^{-i k \theta}-\sum_{k=3}^{\infty}(k-2) c_{k-2} R_{1}^{-k+2} e^{i k \theta}+\sum_{k=1}^{\infty} d_{k} R_{1}^{-k} e^{i k \theta} \\
& \quad=\sum_{k=1}^{\infty} e_{k} R_{1}^{-k} e^{-i k \theta}+\sum_{k=1}^{\infty} f_{k} R_{1}^{k} e^{i k \theta} \\
& \quad-\sum_{k=3}^{\infty}(k-2) e_{k-2} R_{1}^{-k+2} e^{i k \theta}+f_{1} R_{1} e^{i \theta}+2 f_{2} R_{1}^{2} \\
& +\sum_{k=1}^{\infty}(k+2) f_{k+2} R_{1}^{k+2} e^{-i k \theta}+\sum_{k=1}^{\infty} g_{k} R_{1}^{-k} e^{i k \theta} \\
& +\sum_{k=1}^{\infty} h_{k} R_{1}^{k} e^{-i k \theta}
\end{aligned}
$$

Comparing the coefficients of the items $e^{\mathrm{i} k \theta}$, the following equations can be then obtained:

$$
\begin{aligned}
\mathrm{d}_{k} R_{1}^{-k-1}= & 2 f_{1} R_{1}+\mathrm{g}_{1} R_{1}^{-1} \\
\mathrm{c}_{k} R_{1}^{-k}= & e_{k} R_{1}^{-k}+(k+2) f_{k+2} R_{1}^{k+2} \\
& +h_{k} R_{1}^{k}, \quad k \geq 1 \\
-k c_{k} R_{1}^{-k}+d_{k+2} R_{1}^{-k-2}= & f_{k+2} R_{1}^{k+2}-k e_{k} R_{1}^{-k} \\
& +g_{k+2} R_{1}^{-k-2}, \quad k \geq 1
\end{aligned}
$$

The displacement condition at the interface $\gamma_{2}\left(z=R_{1} e^{\mathrm{i} \theta}\right)$ can be expressed as follows:

$$
u_{\rho}^{\mathrm{R}}+\mathrm{i} u_{\theta}^{\mathrm{R}}=u_{\rho}^{\mathrm{L}}+\mathrm{i} u_{\theta}^{\mathrm{L}}
$$

Substituting (14) - (18) into (27), the displacement condition at $\gamma_{2}$ can be then expressed as the following:

$$
\begin{aligned}
& \frac{(1-\eta) p}{2 G_{1}}\left[\kappa_{1}(1-\lambda) R_{1} e^{-i \theta}-(1+\lambda) R_{1} e^{-i \theta}\right] \\
& +\frac{1}{G_{1}}\left(\kappa_{1}+\frac{G_{1}}{G_{2}}\right) \sum_{k=1}^{\infty} c_{k} R_{1}{ }^{-k} e^{-i k \theta} \\
& -\frac{G_{1} / G_{2}-1}{G_{1}}\left[\sum_{k=3}^{\infty}(k-2) c_{k-2} R_{1}{ }^{-k+2} e^{-i k \theta}\right. \\
& \left.-\sum_{k=1}^{\infty} d_{k} R_{1}{ }^{-k} e^{i k \theta}\right]=\frac{\kappa_{2}+1}{G_{2}}\left[\sum_{k=1}^{\infty} e_{k} R_{1}{ }^{-k} e^{-i k \theta}\right. \\
& \left.+\sum_{k=1}^{\infty} f_{k} R_{1}{ }^{k} e^{i k \theta}\right]
\end{aligned}
$$

Comparing the coefficients of the items $e^{\mathrm{i} k \theta}$ in (28), the following equations can be obtained:

$$
\begin{aligned}
& \frac{(1-\eta) p}{2 G_{1}} \kappa_{1}(1-\lambda) R_{1}+\frac{1}{G_{1}}\left(\kappa_{1}+\frac{G_{1}}{G_{2}}\right) R_{1}{ }^{-1} c_{1} \\
& =\frac{1}{G_{2}}\left(\kappa_{2}+1\right) R_{1}^{-1} e_{1} \\
& -\frac{(1-\eta) p}{2 G_{1}}(1+\lambda) R_{1}+\frac{1}{G_{1}}\left(\frac{G_{1}}{G_{2}}-1\right) R_{1}^{-1} d_{1} \\
& =\frac{1}{G_{2}}\left(\kappa_{2}+1\right) R_{1} f_{1} \\
& \frac{1}{G_{1}}\left(\kappa_{1}+\frac{G_{1}}{G_{2}}\right) c_{k}=\frac{1}{G_{2}}\left(\kappa_{2}+1\right) e_{k}, \quad k \geq 2 \\
& d_{2}=0 \\
& -\frac{G_{1} / G_{2}-1}{G_{1}} c_{k} R_{1}^{-k}+\frac{G_{1} / G_{2}-1}{G_{1}} d_{k+2} R_{1}^{-k-2} \\
& =\frac{1}{G_{2}}\left(\kappa_{2}+1\right) f_{k+2} R_{1}^{k+2}, \quad k \geq 1
\end{aligned}
$$

Eqs. (23), (26), and (29) are the equations to calculate the coefficients of the complex potentials. It can be concluded from (23), (26), and (29) that when $k \geq 2$, the coefficients $c_{k}, d_{k+2}, e_{k}, f_{k+2}, g_{k+2}$, and $h_{k}$ equal zero. Hence, the four unknown complex potentials can be expressed as follows:

$$
\begin{aligned}
& \varphi_{2}(z)=c_{1} z^{-1} \\
& \psi_{2}(z)=d_{1} z^{-1}+d_{3} z^{-3} \\
& \varphi_{3}(z)=e_{1} z^{-1}+f_{1} z+f_{3} z^{3} \\
& \psi_{3}(z)=g_{1} z^{-1}+g_{3} z^{-3}+h_{1} z
\end{aligned}
$$


The remaining nonzero coefficients $c_{1}, d_{1}, d_{3}, e_{1}, f_{1}, f_{3}$,

$$
\mathbf{A B}=\mathbf{C}
$$
$g_{1}, g_{3}$, and $h_{1}$ in (30) can be determined by the following linear equation set derived from (23), (26), and (29):

where

$$
\begin{aligned}
& \mathbf{A}=\left[\begin{array}{lllllllll}
c_{1} & d_{1} & d_{3} & e_{1} & f_{1} & f_{3} & g_{1} & g_{3} & h_{1}
\end{array}\right] \\
& \mathbf{B}=\left[\begin{array}{ccccccccc}
0 & 0 & 0 & \kappa_{1}+\frac{G_{1}}{G_{2}} & 0 & \left(\frac{G_{1}}{G_{2}}-1\right) R_{1}^{2} & 0 & 1 & R_{1}^{2} \\
0 & 0 & 0 & 0 & \frac{G_{1}}{G_{2}}-1 & 0 & 1 & 0 & 0 \\
0 & 0 & 0 & 0 & 0 & 1-\frac{G_{1}}{G_{2}} & 0 & 0 & -1 \\
0 & 1 & R_{0}^{2} & \kappa_{1}-\frac{G_{1}}{G_{2}}\left(\kappa_{2}+1\right) & 0 & 0 & 0 & -1 & -R_{1}^{2} \\
2 R_{0}^{2} & 0 & 0 & 0 & -\frac{G_{1}}{G_{2}}\left(\kappa_{2}+1\right) R_{1}^{2} & 0 & -2 R_{1}^{2} & 0 & 0 \\
0 & 3 R_{0}^{4}-R_{0}^{6} & 0 & 0 & \frac{G_{1}}{G_{2}}\left(\kappa_{2}+1\right) R_{1}^{6} & 0 & -3 R_{1}^{4} & -R_{1}^{6} \\
1 & 0 & 0 & 0 & 0 & 0 & -1 & 0 & 0 \\
0 & 0 & -1 & 0 & 0 & 0 & 0 & 0 & 0 \\
0 & R_{0}^{2} & 0 & 0 & 0 & 0 & -R_{1}^{2} & 0
\end{array}\right] \text {, }
\end{aligned}
$$

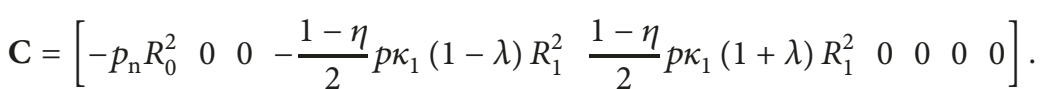

\section{Solutions for the Forces and Displacements}

3.1. Solutions for Stresses of Lining and Rock-Mass. From (20), the stress components for any points of the lining can be obtained by the following equations:

$$
\begin{aligned}
\sigma_{\rho}+\sigma_{\theta} & =4 \operatorname{Re}\left[\varphi_{3}^{\prime}(z)\right] \\
\sigma_{\theta}-\sigma_{\rho}+2 \mathrm{i} \tau_{\rho \theta} & =2\left[\bar{z} \varphi_{3}^{\prime}(z)+\psi_{3}^{\prime}(z)\right] e^{2 \mathrm{i} \theta}
\end{aligned}
$$

Moreover, (33) can be expanded as follows:

$$
\begin{aligned}
\sigma_{\theta} & =2 \operatorname{Re}\left[\varphi_{3}^{\prime}(z)\right]+\operatorname{Re}\left\{\left[\bar{z} \varphi_{3}^{\prime \prime}(z)+\psi_{3}^{\prime}(z)\right] e^{2 \mathrm{i} \theta}\right\} \\
\sigma_{\rho} & =2 \operatorname{Re}\left[\varphi_{3}^{\prime}(z)\right]-\operatorname{Re}\left\{\left[\bar{z} \varphi_{3}^{\prime \prime}(z)+\psi_{3}^{\prime}(z)\right] e^{2 \mathrm{i} \theta}\right\} \\
\tau_{\rho \theta} & =\operatorname{Im}\left\{\left[\bar{z} \varphi_{3}^{\prime \prime}(z)+\psi_{3}^{\prime}(z)\right] e^{2 \mathrm{i} \theta}\right\}
\end{aligned}
$$

Substituting (30) into (34), the stresses in the lining can be obtained by the following:

$$
\begin{aligned}
& \sigma_{\theta}=2 f_{1}-g_{1} \rho^{-2}+\left(12 f_{3} \rho^{-2}-3 g_{3} \rho^{-4}+h_{1}\right) \cos 2 \theta \\
& \sigma_{\rho}=2 f_{1}+g_{1} \rho^{-2}+\left(-4 e_{1} \rho^{-2}+3 g_{3} \rho^{-4}-h_{1}\right) \cos 2 \theta \\
& \tau_{\rho \theta}=\left(6 f_{3} \rho^{2}-2 e_{1} \rho^{-2}+3 g_{3} \rho^{-4}+h_{1}\right) \sin 2 \theta
\end{aligned}
$$

The total stress of the rock-mass is the combination of the stress state before excavation, the stress caused by the tunnel excavation, and the stress caused by the lining support. Hence, combining (23) with (30), the functions can be expressed by the following:

$$
\begin{aligned}
\varphi_{2}(z)= & -\frac{p(1+\lambda)}{4} z+\frac{p(1-\lambda)}{2} R_{1}{ }^{2} z^{-1}+c_{1} z^{-1} \\
\psi_{2}(z)= & -\frac{p(1-\lambda)}{2} z+\frac{p(1+\lambda)}{2} R_{1}{ }^{2} z^{-1} \\
& +\frac{p(1-\lambda)}{2} R_{1}{ }^{4} z^{-3}+d_{1} z^{-1}+d_{3} z^{-3}
\end{aligned}
$$

Substituting (36) into (20), the stresses of the rock-mass can be obtained as follows:

$$
\begin{aligned}
\sigma_{\rho} & =-2(1+\lambda) \frac{p}{2}-\left[(1+\lambda) \frac{p}{2} R_{1}^{2}+d_{1}\right] \rho^{-2} \\
& -\left\{(1-\lambda) \frac{p}{2}+\left[3(1-\lambda) \frac{p}{2} R_{1}^{4}+3 d_{3}\right] \rho^{-4}\right\} \cos 2 \theta \\
\sigma_{\theta} & =-2(1+\lambda) \frac{p}{2}+\left[(1+\lambda) \frac{p}{2} R_{1}^{2}+d_{1}\right] \rho^{-2} \\
& +\left\{(1-\lambda) \frac{p}{2}-2\left[(1-\lambda) p R_{1}^{2}+2 c_{1}\right] \rho^{-2}\right. \\
& \left.+\left[3(1-\lambda) \frac{p}{2} R_{1}^{4}+3 d_{3}\right] \rho^{-4}\right\} \cos 2 \theta \\
\tau_{\rho \theta} & =-\left\{(1-\lambda) \frac{p}{2}+\left[(1-\lambda) p R_{1}^{2}+2 c_{1}\right] \rho^{-2}\right. \\
& \left.-\left[3(1-\lambda) \frac{p}{2} R_{1}^{4}+3 d_{3}\right] \rho^{-4}\right\} \sin 2 \theta
\end{aligned}
$$




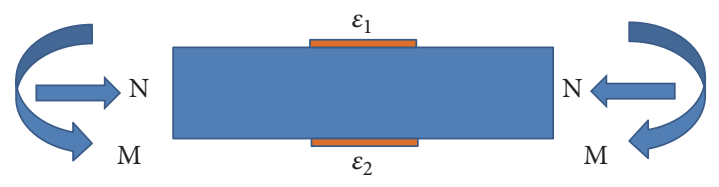

FIGURE 3: Sketch map for lining forces.

3.2. Solutions for Internal Forces. Assume that the tangential stress at different depth of the lining varies linearly along the lining thickness, and the bending moment and axial force of the lining can be obtained based on the tangential stress of the inner and outer boundaries of the lining. The strains under the two boundaries of the lining caused by the bending moment and axial force are shown in Figure 3.

Strains at the two boundaries can be expressed as follows:

$$
\begin{aligned}
& \varepsilon_{1}=\varepsilon_{\mathrm{N}}-\varepsilon_{\mathrm{M}} \\
& \varepsilon_{2}=\varepsilon_{\mathrm{N}}+\varepsilon_{\mathrm{M}}
\end{aligned}
$$

where $\varepsilon_{1}$ is the strain in the tension side, $\varepsilon_{2}$ is the strain in the compression side, $\varepsilon_{\mathrm{M}}$ is the strain caused by the bending moment, and $\varepsilon_{\mathrm{N}}$ is the strain caused by the axial force.

Furthermore, $\varepsilon_{\mathrm{M}}$ and $\varepsilon_{\mathrm{N}}$ can be calculated by the following equations:

$$
\begin{aligned}
& \varepsilon_{M}=\frac{\left(\varepsilon_{2}-\varepsilon_{1}\right)}{2} \\
& \varepsilon_{\mathrm{N}}=\frac{\left(\varepsilon_{2}+\varepsilon_{1}\right)}{2}
\end{aligned}
$$

According to the mechanics of material, the stress can be obtained as follows:

$$
\sigma=\left\{\begin{array}{l}
\frac{M}{W} \\
\frac{N}{A}
\end{array}\right.
$$

where $W$ is the lining bending rigidity and $A$ is the crosssection area.

Combining (38) - (40), the bending moment and axial force can be expressed as

$$
\begin{aligned}
& M=E_{2} \frac{\varepsilon_{2}-\varepsilon_{1}}{2} W=\frac{\sigma_{\theta 2}-\sigma_{\theta 1}}{2} W \\
& N=E_{2} \frac{\varepsilon_{2}+\varepsilon_{1}}{2} A=\frac{\sigma_{\theta 2}+\sigma_{\theta 1}}{2} A
\end{aligned}
$$

where $\sigma_{\theta 1}$ is the tangential stress on the tension side and $\sigma_{\theta 2}$ is the tangential stress on the compression side.

3.3. Solutions for Displacements. From (18), the displacement components of the lining can be expressed as follows:

$$
\begin{aligned}
& u_{\rho}{ }^{\mathrm{L}}=\operatorname{Re}\left\{\frac{1}{2 G_{2}} e^{-\mathrm{i} \theta}\left[\kappa_{2} \varphi_{3}(z)-z \overline{\varphi_{3}{ }^{\prime}(z)}-\overline{\psi_{3}(z)}\right]\right\} \\
& u_{\theta}{ }^{\mathrm{L}}=\operatorname{Im}\left\{\frac{1}{2 G_{2}} e^{-\mathrm{i} \theta}\left[\kappa_{2} \varphi_{3}(z)-z \overline{\varphi_{3}{ }^{\prime}(z)}-\overline{\psi_{3}(z)}\right]\right\}
\end{aligned}
$$

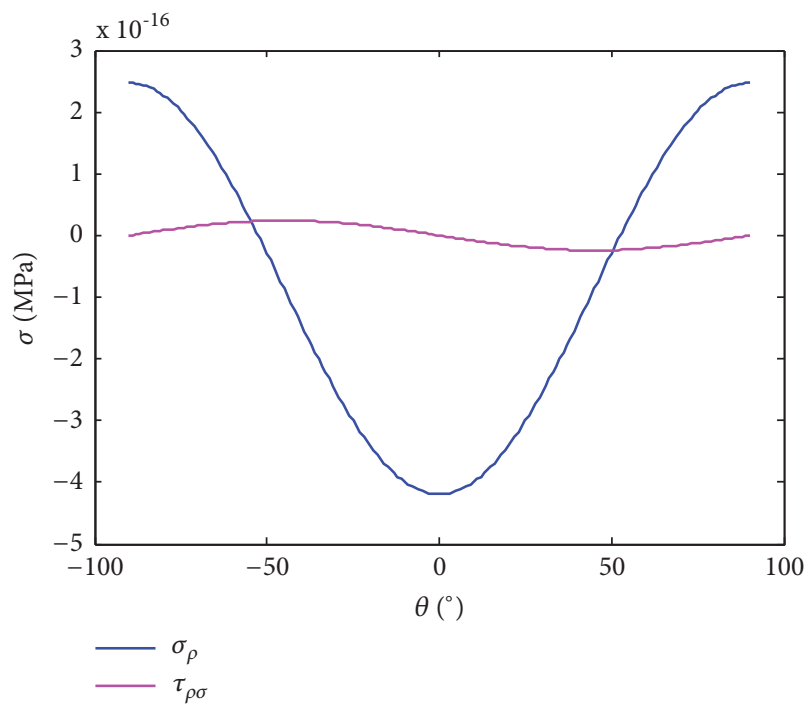

FIGURE 4: Normal and shear stress of the lining inner boundary.

From (17), the displacement components of the surrounding rock-mass can be expressed as

$$
\begin{aligned}
u_{\rho}{ }^{\mathrm{R}} & =\operatorname{Re}\left\{\frac{1-\eta}{2 G_{1}} e^{-\mathrm{i} \theta}\left[\kappa_{1} \varphi_{1}(z)-z \overline{\varphi_{1}^{\prime}(z)}-\overline{\psi_{1}(z)}\right]\right. \\
& \left.+\frac{1}{2 G_{1}} e^{-\mathrm{i} \theta}\left[\kappa_{1} \varphi_{2}(z)-z \overline{\varphi_{2}{ }^{\prime}(z)}-\overline{\psi_{2}(z)}\right]\right\} \\
u_{\theta}{ }^{\mathrm{R}} & =\operatorname{Im}\left\{\frac{1-\eta}{2 G_{1}} e^{-\mathrm{i} \theta}\left[\kappa_{1} \varphi_{1}(z)-z \overline{\varphi_{1}^{\prime}(z)}-\overline{\psi_{1}(z)}\right]\right. \\
& \left.+\frac{1}{2 G_{1}} e^{-\mathrm{i} \theta}\left[\kappa_{1} \varphi_{2}(z)-z \overline{\varphi_{2}{ }^{\prime}(z)}-\overline{\psi_{2}(z)}\right]\right\}
\end{aligned}
$$

\section{Example and Discussion}

In this section, the parameters are taken as follows: $R_{0}=3 \mathrm{~m}$; $R_{1}=3.45 \mathrm{~m} ; E_{1}=10 \mathrm{GPa} ; E_{2}=20 \mathrm{GPa} ; \mu_{1}=0.35 ; \mu_{2}=0.2 ; \eta=0.6$; $p=3 \mathrm{MPa} ; \lambda=0.3 ; p_{\mathrm{n}}=0$.

4.1. Accuracy of the Complex Function Method. It is clear that the reality shear stress component in the free boundary of the tunnel inner surface equals zero and the reality normal stress component equals $-p_{\mathrm{n}}\left(-p_{\mathrm{n}}\right.$ here equals zero $)$. Also, the reality displacements of the lining and rock-mass interface from both lining side and rock-mass side are continuous. The calculated shear stress $\tau_{\rho \theta}$ and normal stress $\sigma_{\rho}$ of the inner surface of the lining by the proposed method were presented in Figure 4. From Figure 4, the calculated $\tau_{\rho \theta}$ was in the range of $-1 \times 10^{-16} \sim 1 \times 10^{-16}$ and $\sigma_{\rho}$ was in the range of $-5 \times 10^{-16} \sim$ $3 \times 10^{-16}$. Both results were close to the reality value "zero" which means the proposed method has a high accuracy to satisfy the boundary conditions at $\gamma_{1}$.

The calculated radial displacement and tangential displacement of the lining and surrounding rock-mass at the interface $\gamma_{2}$ were shown in Figures 5 and 6 . It can be seen 


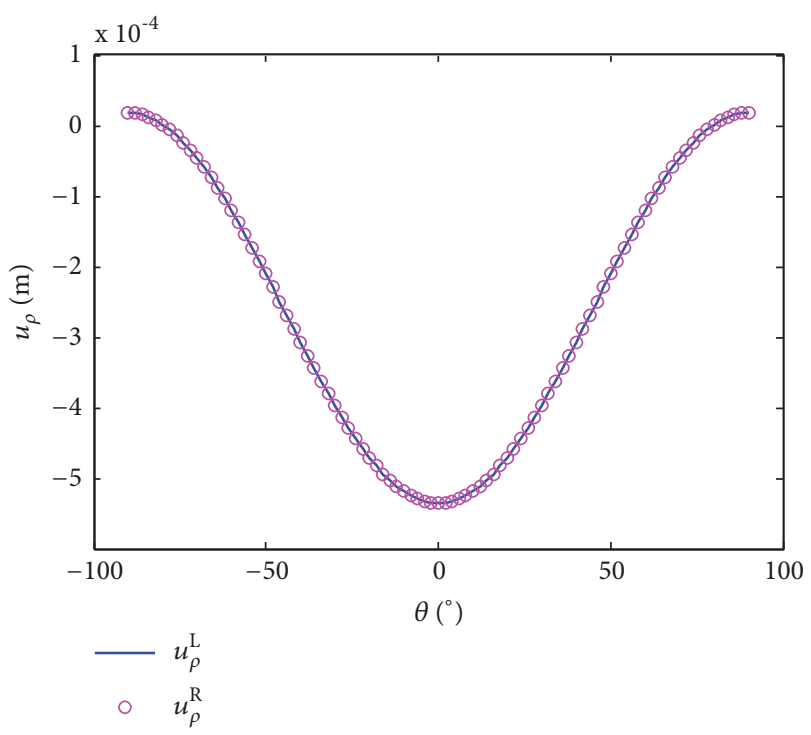

FIGURE 5: Radial displacement along $\gamma_{2}$.

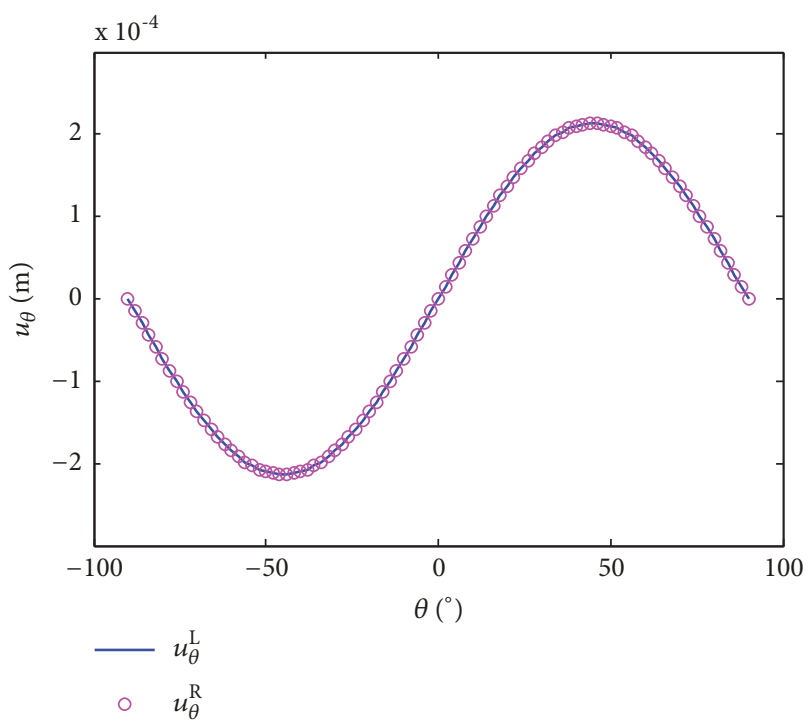

Figure 6: Tangential displacement along $\gamma_{2}$.

that the displacement of the lining and rock-mass were in perfect agreement. Thus, calculation results of the proposed method satisfied the displacement boundary condition very well. The proposed complex variable method is accurate enough to establish solutions for the deeply buried lined tunnels excavated in the homogenous elastic rock-mass.

4.2. Lining Forces and Discussion. The tangential stress of the lining at the two boundaries $\gamma_{1}$ and $\gamma_{2}$ was shown in Figure 7 . Both tangential stresses at $\gamma_{1}$ and $\gamma_{2}$ were negative which means the whole part of the tunnel lining was under a compression state. Both of the stresses showed the same variation trend with $\theta$, but the stress at the inner boundary fluctuated more than the outer boundary. There were two intersection points of the two stresses at $34^{\circ}$ and $56^{\circ}$ from the

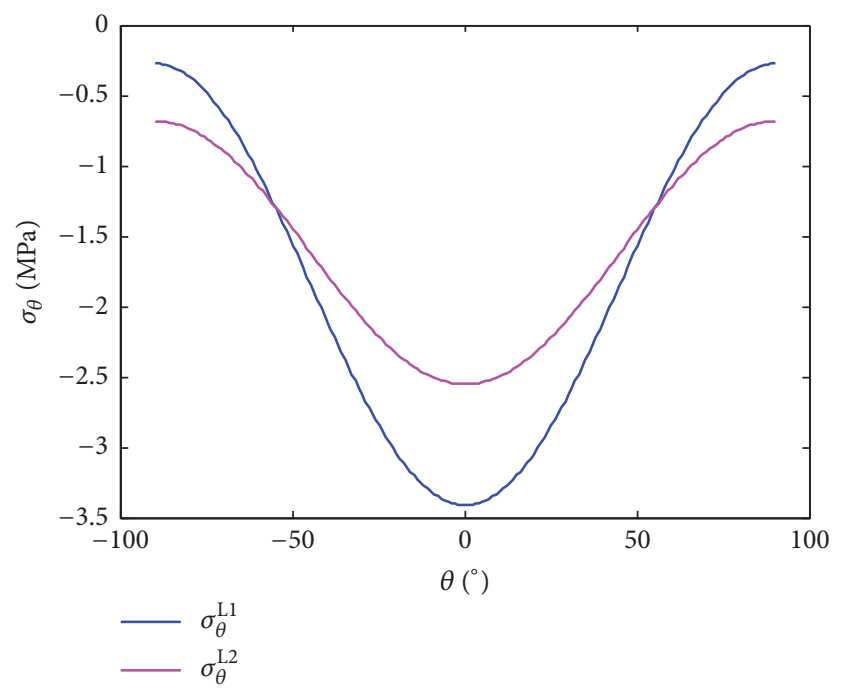

Figure 7: Tangential stress of the lining at $\gamma_{1}$ and $\gamma_{2}$.

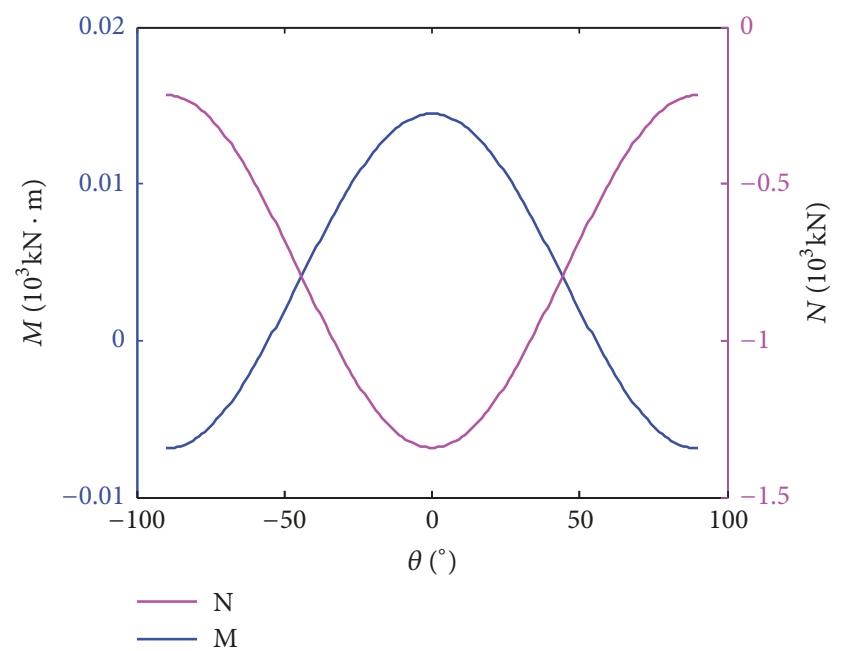

FIGURE 8: Bending moment and axial force of the lining.

tunnel crown to the invert. Also, the positive and negative of the bending moment changed at the two intersection points as shown in Figure 8. The maximum bending moment occurred at $90^{\circ}$ from the tunnel crown to the invert with the value of $14.5 \mathrm{kN} \cdot \mathrm{m}$ and the corresponding minimum at the tunnel crown and invert with the value of $-6.9 \mathrm{kN} \cdot \mathrm{m}$. The axial force is positive (under compression state) among the whole part of the lining. The minimum axial force occurred at the tunnel crown and invert with the same value of $216.2 \mathrm{kN}$ and the maximum at $90^{\circ}$ from the tunnel crown to invert with the value of $1341 \mathrm{kN}$.

In order to estimate the failure mode of the lining beam, a safety coefficient Fs is introduced as follows:

$$
F \mathrm{~s}=\frac{\sigma_{t}}{\sigma_{\theta 1}}=\frac{\sigma_{c}}{\sigma_{\theta 2}}
$$

where $\sigma_{t}$ is the tensile strength and $\sigma_{c}$ is the compressive strength. 


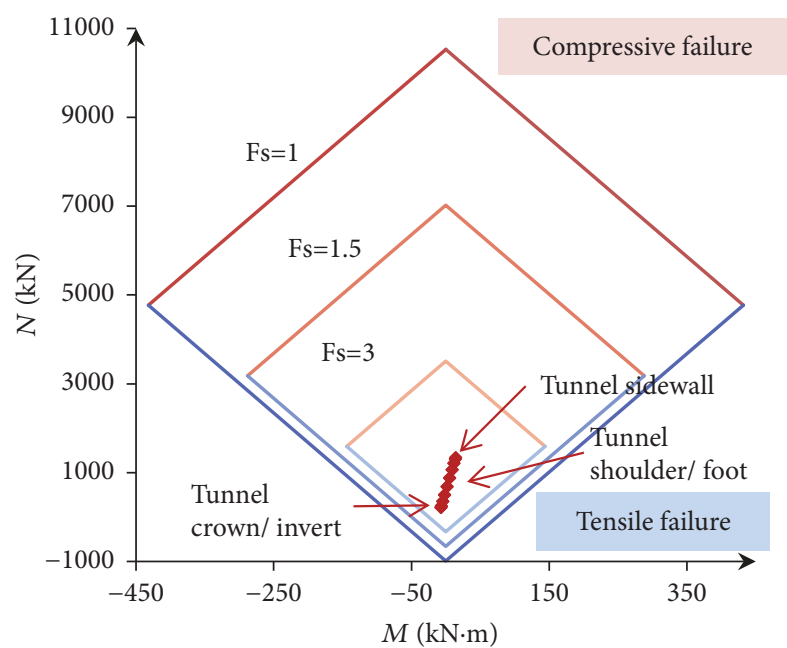

FIGURE 9: Compression-bending capacity diagram of the lining.

Assume that the concrete is $\mathrm{C} 35$, the tensile strength $\sigma_{t}$ is $-2.2 \mathrm{MPa}$, and the compressive strength $\sigma_{c}$ is $23.4 \mathrm{MPa}$. The compression-bending capacity diagram of the lining under different $F_{\mathrm{s}}$ was shown in Figure 9. From Figure 9, the safety coefficient of the example tunnel was greater than 3 , which presented the thickness of the lining is safe enough and even can be decreased. The tunnel shoulders and tunnel feet were the safest part of the lining. Compared with the tunnel shoulders and feet, the safety coefficient of the tunnel crown and invert, as well as the tunnel sidewall, was smaller. Tensile failure was more likely to occur in the tunnel crown and invert while compressive failure was more likely to occur in the tunnel sidewall. In general, the lining structure had greater potential to avoid compressive failure than to avoid tensile failure. Thus, tensile resistance design of the lining should be applied in the tunnel especially the crown and invert part to avoid the structure failure.

Figure 10 is the $3 \mathrm{D}$ surface plot of the tangential stress in different depth of the lining. From the projection of the $3 \mathrm{D}$ surface on the $x-o-z$ plane $\left(\theta-o-\sigma_{\theta}\right.$ plane), the tangential stress of different layers of lining intersected with each other at the same $\theta\left(-56^{\circ}\right.$ and $\left.56^{\circ}\right)$ where the cross-sections were in the pure compression stress state. The bending moment at the two sections was zero. From the projection of the $3 \mathrm{D}$ surface on the $y-o-z$ plane ( $t-o-\sigma_{\theta}$ plane), a linear relationship between lining thickness and tangential stress could be found and provided evidence for the assumption in Section 3.2.

The relationships between the tangential stresses and the parameters $\theta$ and $\lambda$ at the two boundaries of the lining were shown in Figures 11 and 12. The coefficient of lateral earth pressure $\lambda$ had shown a great influence on tangential stresses of the lining. The 3D surface projection on the $y-o-z$ plane showed a various linear relationship between the coefficient of lateral earth pressure and the tangential stress with different $\theta$. The slope of the tangential stress at the inner boundary was steeper than that of the out boundary. From the projection on the $x-o-y$ plane, positive tangential stress (tensile stress) occurred when $\lambda$ was smaller than 0.4 . Thus, for tunnels built in soil with small lateral earth pressure coefficient,

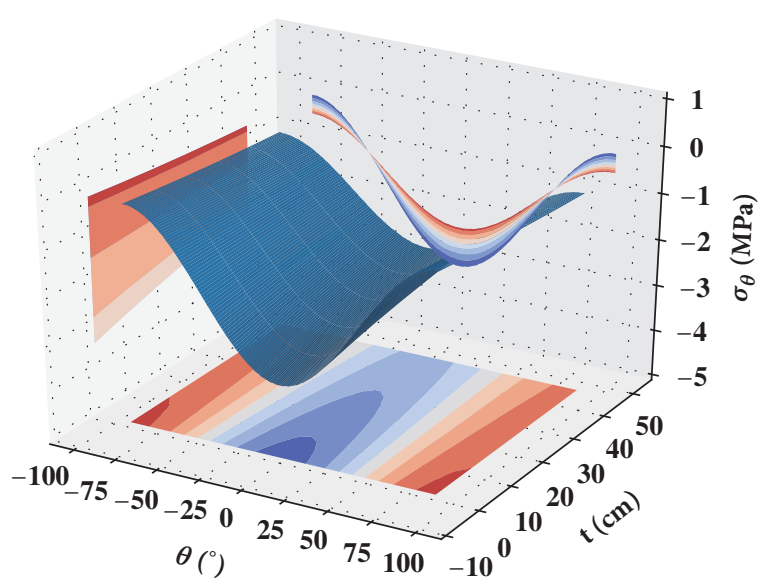

FIgURE 10: Tangential stress of the lining at different depth.

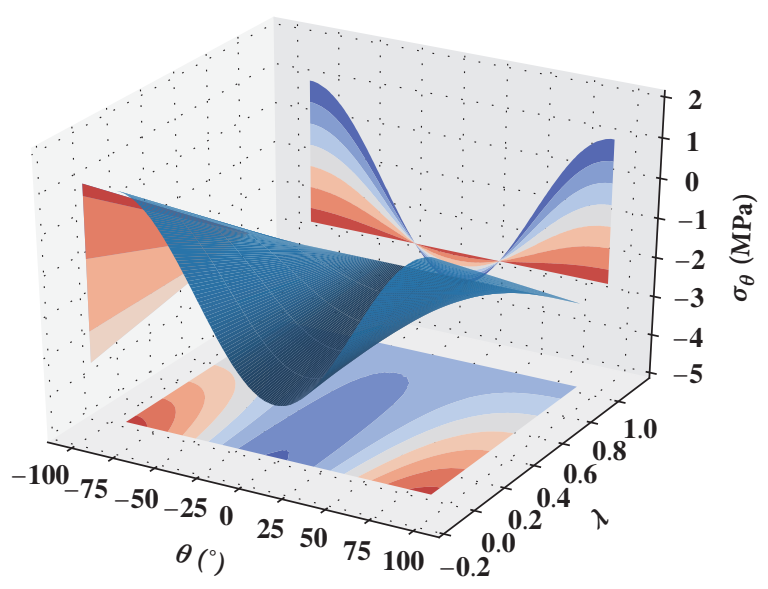

FIGURE 11: Tangential stress of the lining with different $\theta$ and $\lambda$ at $\gamma_{1}$.

reinforced concrete or fibre concrete linings rather than plain concrete linings should be applied to enhance the durability of the tunnel. It can be seen from the projection on the $x-o-z$ plane that the negative tangential stress occurred where $\theta$ was between $-78^{\circ} \sim-102^{\circ}$ and $168^{\circ} \sim 192^{\circ}$. These parts were the tunnel crown and invert. Therefore, tension-resistant design should be mainly applied to the tunnel crown and invert. In addition, when $\lambda$ equalled 1 , the tangential stress of both boundaries remained unchanged at arbitrary $\theta$.

4.3. Rock-Mass Stresses and Discussion. In order to analyse the stress state of the rock-mass, the horizontal and vertical stress components can be obtained by the following equation:

$$
\begin{aligned}
\sigma_{x} & =\frac{\sigma_{\rho}+\sigma_{\theta}}{2}+\frac{\sigma_{\rho}-\sigma_{\theta}}{2} \cos 2 \theta-\tau_{\rho \theta} \sin 2 \theta \\
\sigma_{y} & =\frac{\sigma_{\rho}+\sigma_{\theta}}{2}-\frac{\sigma_{\rho}-\sigma_{\theta}}{2} \cos 2 \theta+\tau_{\rho \theta} \sin 2 \theta \\
\tau_{x y} & =\frac{\sigma_{\rho}-\sigma_{\theta}}{2} \sin 2 \theta+\tau_{\rho \theta} \cos 2 \theta
\end{aligned}
$$

The horizontal and vertical stresses of the rock-mass were shown in Figures 13 and 14, respectively. From Figures 


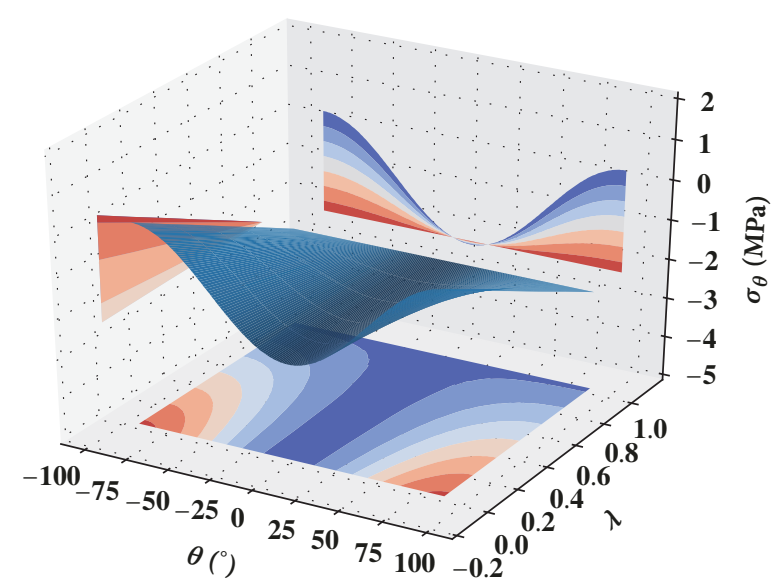

FIGURE 12: Tangential stress of the lining with different $\theta$ and $\lambda$ at $\gamma_{2}$.

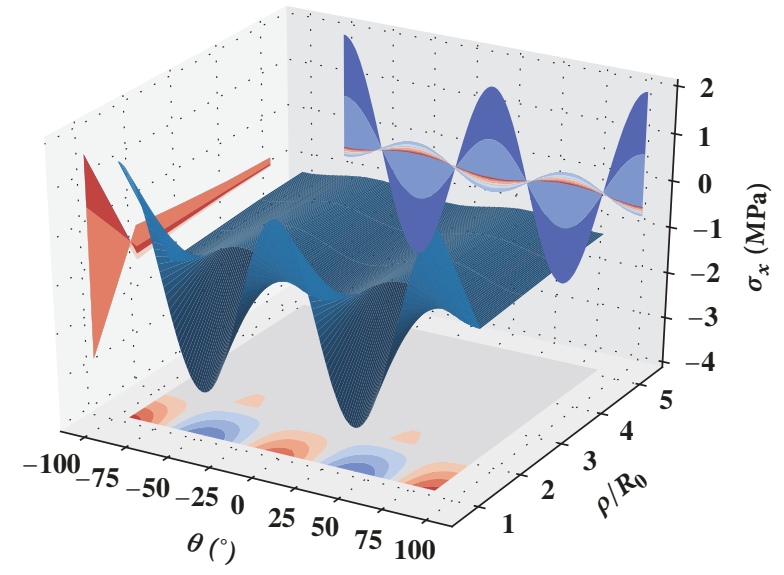

FIGURE 13: Horizontal stress of the lining with different $\theta$ and $\rho$ at $\gamma_{2}$.

13 and 14 , the stresses declined sharply when $\rho / R_{0}$ was smaller than 2 . Then the horizontal stress and vertical stress changed slowly and tended to the initial stress state $(\lambda p$ and $p$, respectively). Therefore, the tunnel excavation and lining support had a limited impact on the surrounding rock-mass. The boundary of the FEM model should be at least twice the tunnel excavation radii to acquire accurate results.

The surrounding rock-mass will be in an unstable state when the tangential stress equals zero [24]. The tangential stress of the rock-mass at $\gamma_{2}$ was calculated and shown in Figure 15. When the coefficient of the lateral pressure was between 0 and 0.3 , the zero value of the tangential stress occurred where $\theta$ was between $-60^{\circ}$ to $-120^{\circ}$ and $60^{\circ}$ to $120^{\circ}$. Therefore, supporting of the surrounding rock-mass in these regions should be enhanced to avoid the collapse during the tunnel excavation.

\section{Conclusion}

An elastic plane strain solution for lined circular tunnels was presented based on the complex variable method. Stress and displacement components solutions were proposed by

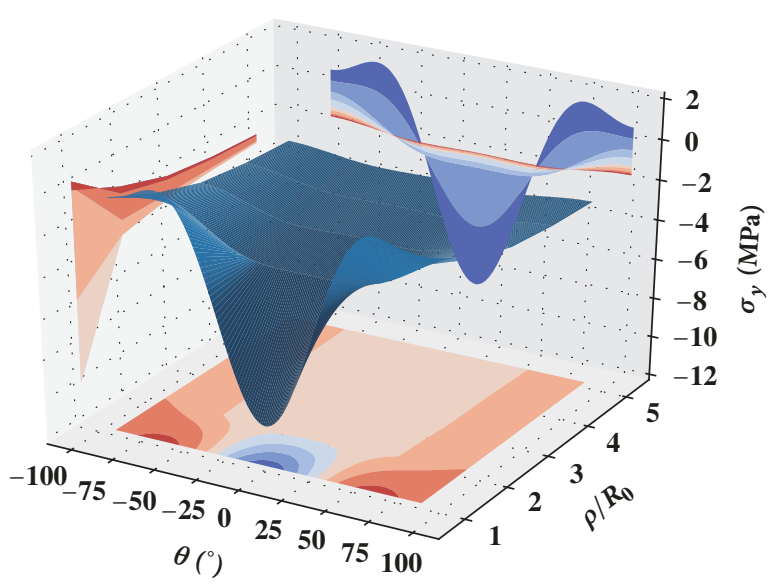

FIGURE 14: Vertical stress of the lining with different $\theta$ and $\rho$ at $\gamma_{2}$.

employing complex potential functions which were determined by the series solution method. Forces solutions for linings were also presented by using the tangential stress at the two boundaries. Some regulations and guidelines for the excavation and design of the tunnel were finally established through the example.

For the linings, the safety coefficient of the tunnel crown and invert, as well as the tunnel sidewall, is smaller compared to that of the tunnel shoulders and feet. Tensile failure was more likely to occur in the tunnel crown and invert while compressive failure was more likely to occur in the tunnel sidewall. The lining structure has a greater potential to avoid compressive failure than to avoid tensile failure. Tensile resistance design of the lining should be applied in the tunnel especially the crown and invert part. For tunnels built in soil with small lateral earth pressure coefficient (especially $\lambda<$ 0.4 ), reinforced concrete or fibre concrete linings rather than plain concrete linings should be applied.

As to the rock-mass, the tunnel excavation and lining support have a great impact on the stress redistribution of the rock-mass. The influence scope is about twice the tunnel excavation radii. When the coefficient of the lateral pressure was between 0 and 0.3 , the zero value of the tangential stress occurred where $\theta$ is between $-60^{\circ}$ to $-120^{\circ}$ and $60^{\circ}$ to $120^{\circ}$. Supporting of the surrounding rock-mass in these regions should be enhanced.

\section{Data Availability}

The data used to support the findings of this study are included within the article.

\section{Conflicts of Interest}

The authors declare that they have no conflicts of interest.

\section{Acknowledgments}

The research work reported herein was made possible by the China Scholarship Council (no. 201706560008). The financial support is highly appreciated. The authors would like to 


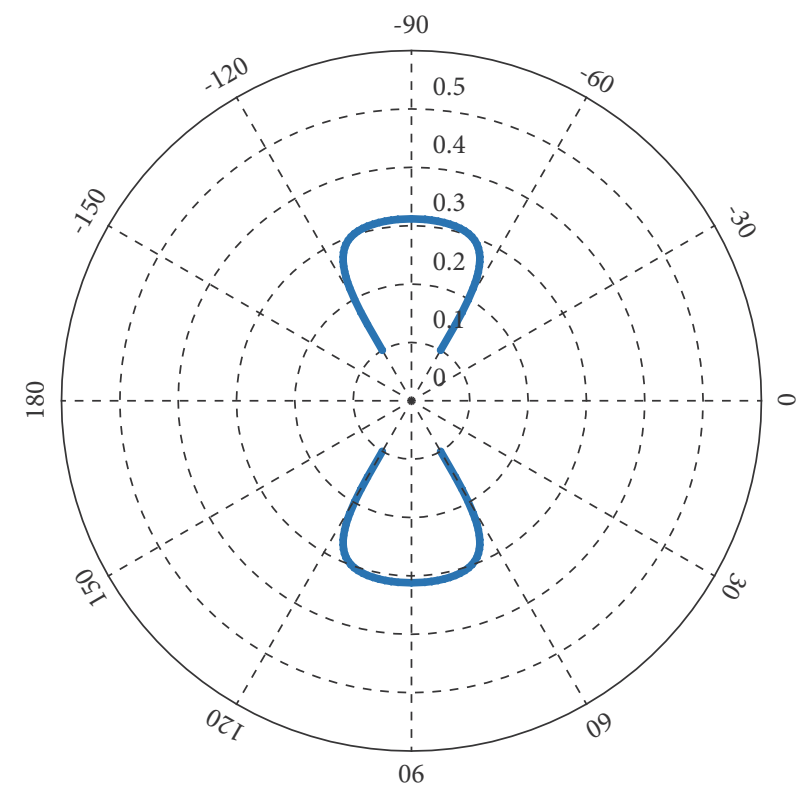

FIGURE 15: Relationship between $\theta$ and $\lambda$ of the interface from the rock side while $\sigma_{\theta}=0$.

express special thanks to Prof. Wei Gao and Dr. Yatong Nie from University of New South Wales for their assistance.

\section{References}

[1] A.-Z. Lu, N. Zhang, and L. Kuang, "Analytic solutions of stress and displacement for a non-circular tunnel at great depth including support delay," International Journal of Rock Mechanics and Mining Sciences, vol. 70, pp. 69-81, 2014.

[2] W. Ming-Bin and L. Shu-Chai, "A complex variable solution for stress and displacement field around a lined circular tunnel at great depth," International Journal for Numerical and Analytical Methods in Geomechanics, vol. 33, no. 7, pp. 939-951, 2009.

[3] A. R. Kargar, R. Rahmannejad, and M. A. Hajabasi, "A semianalytical elastic solution for stress field of lined non-circular tunnels at great depth using complex variable method," International Journal of Solids and Structures, vol. 51, no. 6, pp. 14751482, 2014.

[4] A. R. Kargar, R. Rahmannejad, and M. A. Hajabasi, "The stress state around lined non-circular hydraulic tunnels below the water table using complex variable method," International Journal of Rock Mechanics and Mining Sciences, vol. 78, pp. 207-216, 2015.

[5] F. Ye, C. F. Gou, H. D. Sun, Y. P. Liu, Y. X. Xia, and Z. Zhou, "Model test study on effective ratio of segment transverse bending rigidity of shield tunnel," Tunnelling and Underground Space Technology, vol. 41, no. 1, pp. 193-205, 2014.

[6] F. Song, H. Wang, and M. Jiang, "Analytical solutions for lined circular tunnels in viscoelastic rock considering various interface conditions," Applied Mathematical Modelling: Simulation and Computation for Engineering and Environmental Systems, vol. 55, pp. 109-130, 2018.

[7] H. N. Wang, M. J. Jiang, T. Zhao, and G. S. Zeng, "Viscoelastic solutions for stresses and displacements around non-circular tunnels sequentially excavated at great depths," Acta Geotechnica, pp. 1-29, 2018.
[8] J. Lai, S. Mao, J. Qiu et al., "Investigation progresses and applications of fractional derivative model in geotechnical engineering," Mathematical Problems in Engineering, vol. 2016, 15 pages, 2016.

[9] J. L. Qiu, Y. Y. Xie, H. B. Fan, Z. C. Wang, and Y. W. Zhang, "Centrifuge modelling of twin-tunnelling induced ground movements in loess strata," Arabian Journal of Geosciences, vol. 10, no. 22, 2017.

[10] S. C. Möller and P. A. Vermeer, "On numerical simulation of tunnel installation," Tunnelling and Underground Space Technology, vol. 23, no. 4, pp. 461-475, 2008.

[11] X. Liu, Y. Liu, Z. Yang, and C. He, "Numerical analysis on the mechanical performance of supporting structures and ground settlement characteristics in construction process of subway station built by Pile-Beam-Arch method," KSCE Journal of Civil Engineering, vol. 21, no. 5, pp. 1690-1705, 2017.

[12] V. Avgerinos, D. M. Potts, and J. R. Standing, "Numerical investigation of the effects of tunnelling on existing tunnels," Géotechnique, vol. 67, no. 9, pp. 808-822, 2017.

[13] A.-Z. Lu, L.-Q. Zhang, and N. Zhang, "Analytic stress solutions for a circular pressure tunnel at pressure and great depth including support delay," International Journal of Rock Mechanics and Mining Sciences, vol. 48, no. 3, pp. 514-519, 2011.

[14] Xingbo Han and Yongxu Xia, "Analytic Solutions of the Forces and Displacements for Multicentre Circular Arc Tunnels," Mathematical Problems in Engineering, vol. 2018, Article ID 8409129, 14 pages, 2018.

[15] Z. G. Zhang, M. S. Huang, X. G. Xi, and X. Yang, "Complex Variable Solutions for Soil and Liner Deformation due to Tunneling in Clays," International Journal of Geomechanics, vol. 18, no. 7, p. 19, 2018.

[16] Y.-L. Pi, M. A. Bradford, and B. Uy, "In-plane stability of arches," International Journal of Solids and Structures, vol. 39, no. 1, pp. 105-125, 2001.

[17] W. Gao, D. Wu, K. Luo, and Y.-L. Pi, "Stochastic behaviour of shallow concrete-filled steel tubular arches," in Proceedings of the 23rd Australasian Conference on the Mechanics of Structures 
and Materials (ACMSM23), pp. 663-668, Byron Bay, Australia, 2014.

[18] N. I. Muskhelishvili and J. R. M. Radok, Some Basic Problems of the Mathematical Theory of Elasticity, Cambridge University Press, London, UK, 1953.

[19] S. G. Lekhnitskii, “Anisotropic plates," Foreign Technology Div Wright-Patterson Afb Oh, 1968.

[20] A. Verruijt, "A complex variable solution for a deforming circular tunnel in an elastic half-plane," International Journal for Numerical and Analytical Methods in Geomechanics, vol. 21, no. 2, pp. 77-89, 1997.

[21] T. M. Vu, J. Sulem, D. Subrin, and N. Monin, "Semi-analytical solution for stresses and displacements in a tunnel excavated in transversely isotropic formation with non-linear behavior," Rock Mechanics and Rock Engineering, vol. 46, no. 2, pp. 213229, 2013.

[22] A. Z. Lu and L. Q. Zhang, Complex Function Method on Mechanical Analysis of Underground Tunnel, Science Press, Beijing, China, 2007.

[23] A. H. England, Complex Variable Methods in Elasticity, Courier Corporation, 2003.

[24] F. Cui, L. Wang, and Y.-F. Wang, "Stress Analytic solution for elastic surrounding rock mass of circular tunnels subjected to non axisymmetric loads," Chinese Journal of Underground Space and Engineering, vol. 13, no. 3, pp. 637-642, 2017. 


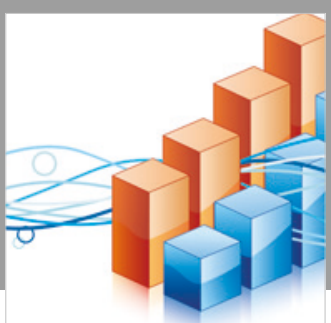

Advances in

Operations Research

\section{-n-m}
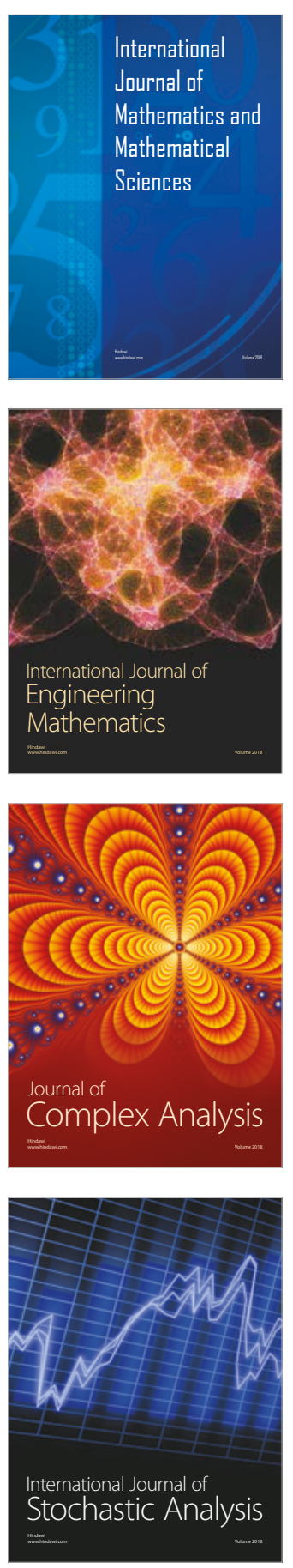
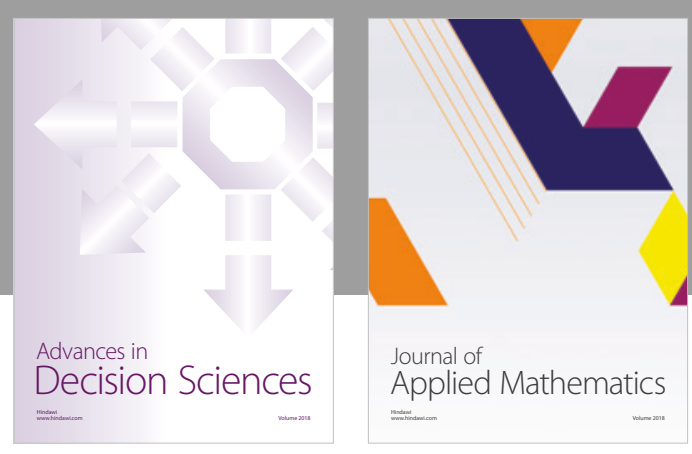

Journal of

Applied Mathematics
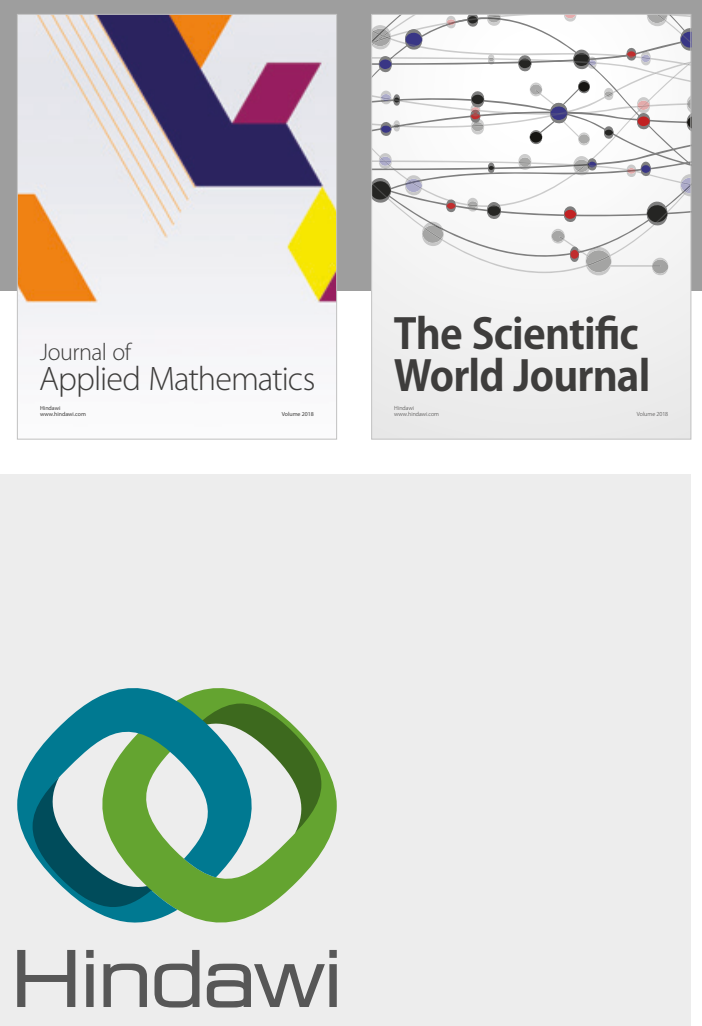

Submit your manuscripts at

www.hindawi.com

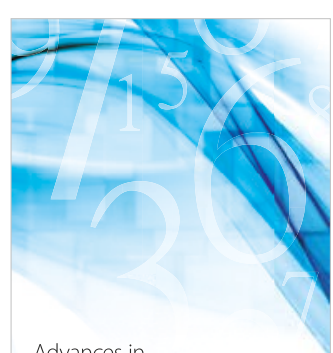

Advances in
Numerical Analysis
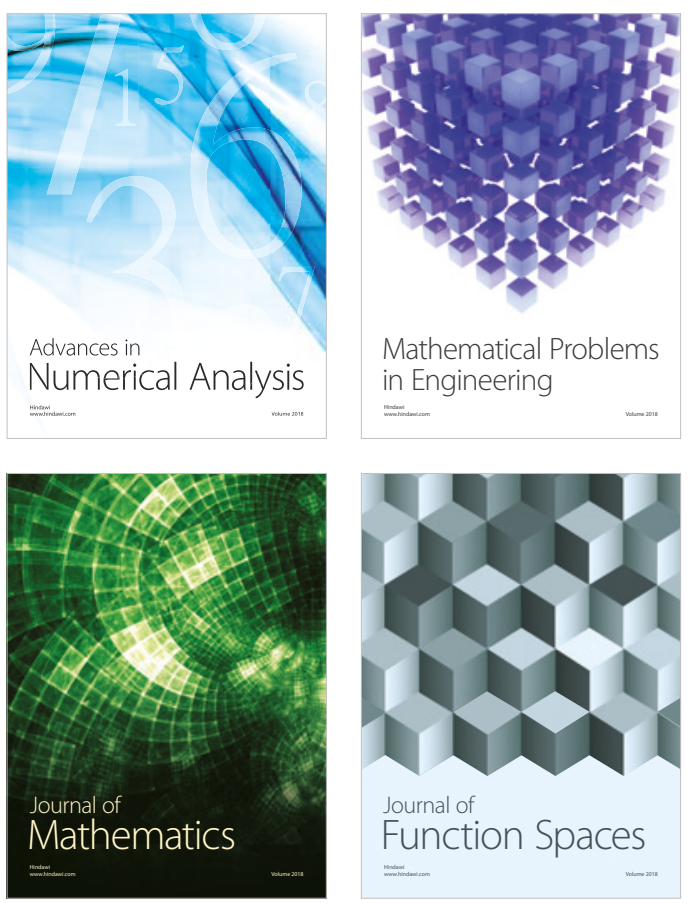

Mathematical Problems in Engineering

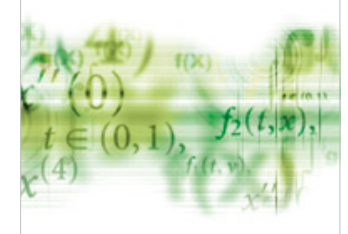

International Journal of

Differential Equations

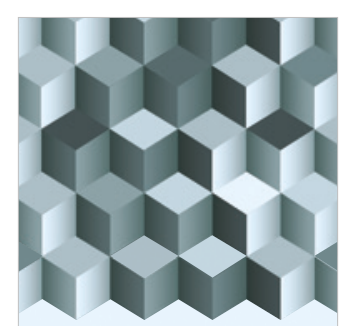

Journal of

Function Spaces

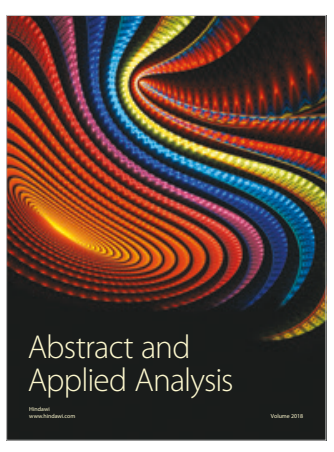

The Scientific

World Journal

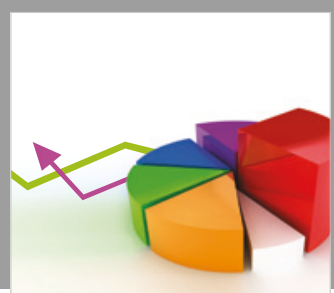

Journal of

Probability and Statistics
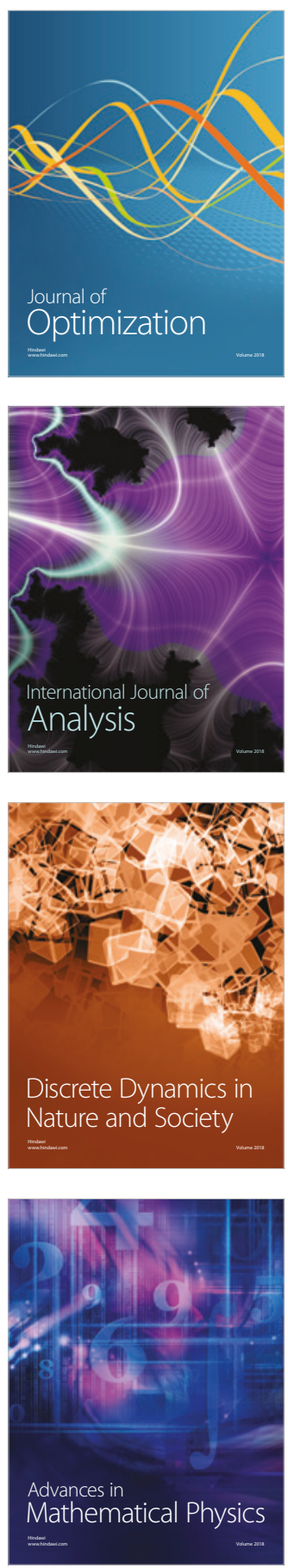